\title{
SH003 selectively induces p73-dependent apoptosis in triple-negative breast cancer cells
}

\author{
EUN KYOUNG CHOI ${ }^{1,2^{*}}$, SEUNG-MI KIM ${ }^{1-3^{*}}$, SEUNG-WOO HONG $^{1,2,4^{*}}$, JAI-HEE MOON $^{1,2}$, JAE-SIK SHIN $^{1,2}$, \\ JEONG HEE KIM ${ }^{1,2}$, IH-YEON HWANG ${ }^{1,2}$, SOO-A JUNG ${ }^{1,2}$, DAE-HEE LEE ${ }^{1,2}$, EUN YOUNG LEE ${ }^{1,2}$, SEUL LEE ${ }^{1,2}$, \\ HYUNWOO KIM ${ }^{1,2}$, DAEJIN KIM ${ }^{4}$, YEONG SEOK KIM ${ }^{4}$, YOUN KYUNG CHOI ${ }^{5}$, HYO IN KIM ${ }^{5}$, HYEONG SIM CHOI $^{5}$, \\ SUNG-GOOK $\mathrm{CHO}^{5}$, JEONG EUN KIM ${ }^{1,2}$, KYU PYO KIM ${ }^{1,2}$, YONG SANG HONG ${ }^{1,2}$, WON KEUN LEE ${ }^{3}$, \\ JUNG SHIN LEE ${ }^{1,2}$, TAE WON KIM ${ }^{1,2}$, SEONG-GYU KO ${ }^{5}$ and DONG-HOON JIN ${ }^{1,2,6}$ \\ ${ }^{1}$ Innovative Cancer Research, ASAN Institute for Life Science; ${ }^{2}$ Department of Oncology, Asan Medical Center, Seoul 138-736; \\ ${ }^{3}$ Division of Biosciences and Bioinformatics, Myongji University, Youngin, Kyunggi-Do 449-728; \\ ${ }^{4}$ Department of Anatomy and Research Center for Tumor Immunology, Inje University College of Medicine, Pusan 614-735; \\ ${ }^{5}$ Department of Preventive Medicine, College of Korean Medicine, Kyung Hee University, Seoul 130-701; \\ ${ }^{6}$ Department of Convergence Medicine, University of Ulsan College of Medicine,
}

Asan Medical Center, Seoul 138-736, Republic of Korea

Received July 30, 2015; Accepted August 12, 2016

DOI: $10.3892 / \mathrm{mmr} .2016 .5722$

\begin{abstract}
Triple-negative breast cancer (TNBC) is a breast cancer subtype that has an aggressive phenotype, is highly metastatic, has limited treatment options and is associated with a poor prognosis. In addition, metastatic TNBC has no preferred standard chemotherapy due to resistance to anthracyclines and taxanes. The present study demonstrated that a herbal extract, SH003, reduced cell viability and induced apoptosis in TNBC without cell cytotoxicity. Cell viability was examined using trypan blue exclusion and colony formation assays, which revealed a decrease in the cell viability. Additionally, apoptosis was determined using flow cytometry and a sub-G1 assay, which revealed an increase in the proportion of cells in the sub-G1 phase. The present study investigated the anticancer
\end{abstract}

Correspondence to: Professor Dong-Hoon Jin, Department of Convergence Medicine, University of Ulsan College of Medicine, Asan Medical Center, 88 Olympicro-43-gil, Songpa-gu, Seoul 138-736, Republic of Korea

E-mail: inno183@amc.seoul.kr

Professor Seong-Gyu Ko, Department of Preventive Medicine, College of Korean Medicine, Kyung Hee University, 1 Hoegi, Seoul 130-701, Republic of Korea

E-mail: epiko@khu.ac.kr

*Contributed equally

Abbreviations: Am, Astragalus membranaceus; Ag, Angelica gigas; Tk, Trichosanthes kirilowii Maximowicz, TNBC, triple-negative breast cancer

Key words: herbal extract, SH003, p73, apoptosis, TNBC effect of SH003 in the Hs578T, MDA-MB-231 and ZR-751 TNBC cell lines, and in the MCF7 and T47D non-TNBC cell lines. Western blot analysis revealed that the expression levels of poly-ADP-ribose polymerase (PARP) cleavage protein in cells treated with $\mathrm{SH} 003$ were increased dose-dependent manner, indicating that SH003 induced apoptosis via a caspase-dependent pathway. Pre-treatment with the caspase inhibitor Z-VAD reduced SH003-induced apoptosis was examined using trypan blue exclusion. Moreover, SH003 treatment enhanced the p73 levels in MDA-MB-231 cells but not in MCF7 cells. Transfection of p73 small interfering RNA (siRNA) in MDA-MB0231 cells revealed that the apoptotic cell death induced by SH003 was significantly impaired in comparison with scramble siRNA transfected MDA-MB-231 cells. This was examined using trypan blue exclusion and flow cytometry analysis (sub-G1). In addition, SH003 and paclitaxel exhibited synergistic anticancer effects on TNBC cells. The results indicate that SH003 exerts its anticancer effect via p 73 protein induction and exhibits synergistic anticancer effects when combined with paclitaxel.

\section{Introduction}

Triple-negative breast cancer (TNBC) is one of the most common types of malignant tumors in women worldwide and is now the third leading cause of cancer-related mortality (1). TNBC is characterized by the absence of estrogen receptor (ER), progesterone receptor (PR) and human epidermal growth factor receptor 2 (HER2) (2). Thus, TNBC patients do not benefit from commonly used anti-estrogen and -herceptin-based therapies (3). In addition, patients with TNBC have been reported to have a poorer survival rate, and recurrence and distant metastases occurs more frequently than in patients with other types of breast cancer (4). Recent studies have revealed that TNBC comprises a heterogeneous group of tumors encompassing several molecular subtypes, such as luminal A, luminal B, HER2-enriched, 
claudin-low and basal-like tumors (5-7). Approximately $62 \%$ of basal-like TNBC and $43 \%$ of non-basal-like TNBC exhibit mutations in the tumor suppressor p53 (MTp53). The majority of p53 mutations observed in the tumor are loss-of-function mutations; however, some patients have been shown to exhibit oncogenic gain-of-function mutations. Therefore, targeting p53 may be less effective in TNBC treatment (8). Thus, successful treatment of p53-mutant TNBCs remains challenging. Doxorubicin (DOXO) and cisplatin (CDDP) are common treatment options for TNBC. However, acquired resistance and toxicity against these drugs eventually occurs, preventing effective treatment (9). Thus, novel therapies that overcome drug resistance and toxicity in p53-mutant TNBC cases are urgently required.

p73 is a member of the p53 gene family and has been shown to regulate p53 target genes in p53-deficient cancer cells (10). In contrast to p53, p73 is rarely mutated or lost in cancer (11). p53 deficient cancers are partly resistant to chemotherapy; however, not completely chemo-resistant. As p53 deficient cancers have other types of p53 family members such as p73, they may be able to replace the function of p53 in response to DNA damage (12). Therefore, identifying anticancer agents that can activate p73 may provide a chemotherapeutic approach for treating drug-resistant p53-mutant cancers. Recently, nonhydrolyzable ether analog of RRR- $\alpha$-tocopherol in combination with DOXO or CDDP has been reported to target p53-mediated genes in a p73-dependent manner, enhancing the apoptosis of TNBC cells (9).

Traditional herbal medicines have recently been revisited for cancer therapy as herbal extracts or mixtures based on traditional medicines have exhibited anticancer effects with no or fewer side effects compared with current anticancer therapeutics, including chemical compounds and targeted antibodies (13). Previous studies have demonstrated the anticancer effects of herbal extracts from Astragalus membranaceus (Am), Angelica gigas (Ag) and Trichosanthes kirilowii Maximowicz (Tk) in different cancer cell types, such as leukemia, hepatocellular carcinoma, colon cancer, non-small cell lung cancer and gastric cancer cells (14-19). Furthermore, extracts from a mixture of Am and Ag have been shown to affect various diseases, including hematological diseases and endocrine disorders (20-22).

The present study demonstrated that $\mathrm{SH} 003$ extracted from a herbal mixture (Am, Ag and Tk) exhibited anticancer effects on TNBC via activation of the p73 pathway. Thus, SH003 may be useful for the treatment of TNBC.

\section{Materials and methods}

Cell culture and reagents. Established Hs578T, MDA-MB-231, ZR-75-1, MCF7 and T47D human breast cancer cell lines were purchased from the American Type Culture Collection (Manassas, VA, USA). All cell lines were maintained in RPMI-1640 medium (Gibco, Thermo Fisher Scientific Inc., Waltham, MA, USA) supplemented with $10 \%$ fetal bovine serum (FBS; Gibco, Thermo Fisher Scientific Inc.), 100 units of penicillin and $100 \mu \mathrm{l} / \mathrm{ml}$ streptomycin. All cells were cultured in a $5 \% \mathrm{CO}_{2}$ incubator at $37^{\circ} \mathrm{C}$. $\mathrm{SH} 003$ was extracted from Am, Ag or Tk, which were provided by Dr S.G. Ko (College of Korean Medicine, University of Kyung Hee, Seoul, Korea) as previously described (23).
Cell viability and cell death analysis. Cells $\left(2 \times 10^{5}\right.$ cells per plate) were seeded in a $60-\mathrm{mm}$ plate and treated with various concentrations of SH003 (50, 100 or $200 \mu \mathrm{g} / \mathrm{ml})$ for $48 \mathrm{~h}$. Cell viability and cell death were assessed using a trypan blue exclusion method. Cell pellet was harvested and resuspend in $1 \mathrm{ml}$ of phosphate-buffered saline (PBS). A total of $10 \mu 10.4 \%$ trypan blue was gently mixed with $10 \mu \mathrm{l}$ cell suspension. The mixture was applied to a hemocytometer and the number of trypan blue stained and non-stained cells were counted under a light microscope. The percentage of viable cells was calculated.

Colony formation assay. Cells were seeded at a density of $3 \times 10^{2}$ cells per well in a 6 -well plate and were treated with various concentrations of $\mathrm{SH} 003(50,100$ or $200 \mu \mathrm{g} / \mathrm{ml})$ for $24 \mathrm{~h}$. The cells were cultured for 14 days and colonies were fixed with $4 \%$ paraformaldehyde and stained with a $0.01 \%$ crystal violet. Colony counts were performed manually using a light microscope and images of each plate were obtained.

RNA interference. Cells were transiently transfected with small interfering (si)RNA using the Lipofectamine RNAi MAX reagent (Invitrogen, Thermo Fisher Scientific, Inc., Waltham, MA, USA) according to the manufacturer's protocol. The siRNA sequence for transfection was p73-siRNA, 5'-GCA AUAAUCUCUCGCAGUAUU-3' and scramble-siRNA, 5'-GGACUCUCGGAUUGUAAGAUU-3'

Western blot analysis. Cell lysates were prepared with radioimmunoprecipitation assay (RIPA) lysis buffer (50 mM Tris-HCl, $\mathrm{pH} 7.5 ; 50 \mathrm{mM} \mathrm{NaCl}, 1 \mu \mathrm{M}$ EGTA and $1 \%$ Triton $\mathrm{X}-100$ ) containing a protease inhibitor cocktail. Protein concentrations in extracts were determined using a Bradford assay (Bio Rad Laboratories, Inc., Hercules, CA, USA). Total cellular proteins (20 $\mu \mathrm{g}$ ) were subjected to $10-15 \%$ sodium dodecyl sulfate-polyacrylamide gel electrophoresis and transferred to polyvinylidene difluoride membranes. The membranes were blocked with $5 \%$ non-fat dry milk in Tris-buffered saline with Tween-20 (TBST) buffer (20 mM Tris-HCl, pH 7.4, $150 \mathrm{mM} \mathrm{NaCl}, 0.1 \%$ Tween-20) and probed with anti-poly ADP ribose polymerase (PARP; cat. no. 9542; 1:1,000), anti-p73 (cat. no. 14620; 1:1,000), anti-caspase 3 (cat. no. 9661; 1:1000; Cell Signaling Technology, Beverly, MA, USA) or anti- $\beta$-actin (cat. no. sc-47778; 1:2,000; Santa Cruz Biotechnology Inc., Dallas, TX, USA) primary antibodies at $4^{\circ} \mathrm{C}$ overnight. Subsequently, the membranes were washed three times with TBST. Primary antibodies were detected following $2 \mathrm{~h}$ incubation at room temperature with a horseradish peroxidase-conjugated anti-mouse (cat. no. 7076; 1:2,000) or anti-rabbit secondary antibody (cat. no. 7074; 1:2,000; Cell Signaling Technology, Danvers, MA, USA). Blots were developed with an enhanced chemiluminescence detection kit (Amersham, Buckinghamshire, UK).

Cell cycle analysis. In total, $3 \times 10^{2}$ cells harvested by trypsinization were fixed in $1 \mathrm{ml}$ of cold $70 \%$ ethanol for $24 \mathrm{~h}$ at $-20^{\circ} \mathrm{C}$. After washing cell pellets with $1 \mathrm{ml} \mathrm{PBS}$, pellets were centrifuged at $300 \mathrm{x}$ g for $5 \mathrm{~min}$, discarded supernatant, resuspended in $1 \mathrm{ml}$ staining solution $(50 \mu \mathrm{g} / \mathrm{ml}$ propidium iodide, $50 \mu \mathrm{g} / \mathrm{ml}$ RNase and $0.1 \%$ Triton $\mathrm{X} 100$ in citrate buffer, $\mathrm{pH} 7.8$ ), incubated for $30 \mathrm{~min}$ and washed with PBS. Cell cycle distribution was analyzed using a FACSCalibur fluorescence-activated cell 


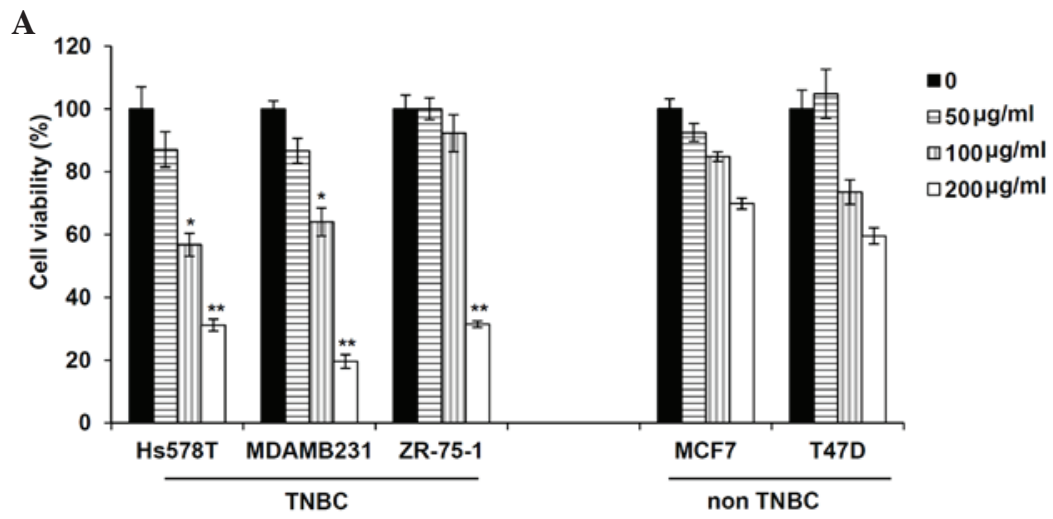

B
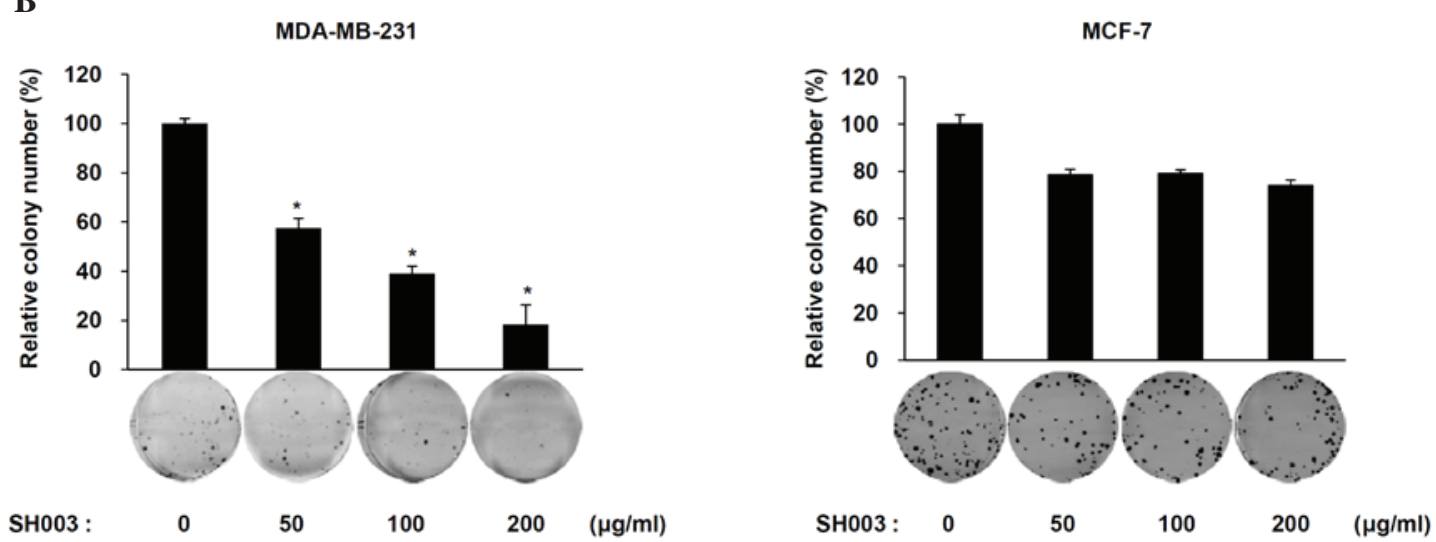

Figure 1. SH003 selectively inhibits the cell viability of TNBC cells. (A) TNBC cell lines (Hs578T, MDA-MB231 and ZR-75-1) and non-TNBC cell lines (MCF-7 and T47D) were treated with the indicated concentrations of SH003, and their cell numbers were assessed by a trypan blue exclusion assay. Data are presented as the mean \pm standard deviation $(n=6)$. ${ }^{*} \mathrm{P}<0.05$ and ${ }^{* *} \mathrm{P}<0.01$, compared with the untreated cells. (B) MDA-MB-231 and MCF-7 cells were pre-treated with the indicated concentrations of SH003 for $24 \mathrm{~h}$. After incubation for 15 days, colonies with $>50$ cells were counted. Data are presented as the mean \pm standard deviation $(\mathrm{n}=3)$. ${ }^{*} \mathrm{P}<0.005$ compared with the non-treated cells. TNBC, triple-negative breast cancer.

sorter and CellQuest version 3.0 software (BD Biosciences, San Jose, CA, USA).

Statistical analysis. SPSS version 22.0 (SPSS, Inc., Chicago, IL, USA) was used to perform statistical analysis. Data are presented as the mean \pm standard deviation and multiple comparisons were conducted using one-way analysis of variance followed by Newman-Keuls post-hoc test. $\mathrm{P}<0.05$ was considered to indicate a statistically significant difference.

\section{Results}

SHOO3 selectively inhibits the cell viability of TNBC cells. The viability of two breast cancer cell types, TNBC (Hs578T, MDA-MB-231 and ZR-75-1) and non-TNBC (MCF7 and T47D) was determined following exposure to SH003. Cells were treated with various concentrations $(50,100$ and $200 \mu \mathrm{g} / \mathrm{ml})$ of SH003. A significant decrease in cell viability was observed in TNBC cells $(\mathrm{P}<0.05$ for the $100 \mu \mathrm{g} / \mathrm{ml}$ group and $\mathrm{P}<0.01$ for the $200 \mu \mathrm{g} / \mathrm{ml}$ group compared with the untreated cells) but not in non-TNBC cells (Fig. 1A). MDA-MB-231 cells were further used as the cells showed the most effectively reduced cell viability in a dose-dependent manner. Additionally, colony formation analyses revealed a significant decrease in the number of MDA-MB-231 (TNBC) cells treated with SH003 but not MCF-7 (non-TNBC) cells (Fig. 1B; P<0.005 compared with the untreated cells). These results indicate that SH003 selectively decreases TNBC cell viability.

SHOO3 induces caspase-dependent cell death in TNBC cells. The effect of SH003 on cell death in MDA-MB-231 cells was determined using flow cytometry. A significant increase in the number of cells at the sub-G1 phase was observed following SH003 treatment (50, 100 and $200 \mu \mathrm{g} / \mathrm{ml})$ (Fig. 2A) $(\mathrm{P}<0.05$ and $\mathrm{P}<0.01$ compared with the untreated cells). Apoptotic cell death and PARP cleavage in response to SH003 treatment were assessed in MDA-MB-231 cells using western blot analysis. The expression levels of cleaved PARP increased significantly in a dose-dependent manner compared with the untreated cells $(\mathrm{P}<0.05$; Fig. 2B). SH003-induced apoptosis after pre-treatment with a pan-caspase inhibitor, Z-VAD was then examined. Pre-treatment with Z-VAD partially decreased the MDA-MB-231 cell death and levels of cleaved PARP induced by $\mathrm{SH} 003$ (Fig. 2C; $\mathrm{P}<0.05$ compared with cells treated with SH003 only). Thus, SH003-induced cell death is partially caspase-dependent in TNBC cells.

Induction of p73 expression by $\mathrm{SHOO3} \mathrm{leads} \mathrm{to} \mathrm{apoptosis} \mathrm{in}$ $T N B C$. A previous study indicated that p73 expression may prevent drug resistance and toxicity in p53-mutant TNBC (8). 
A

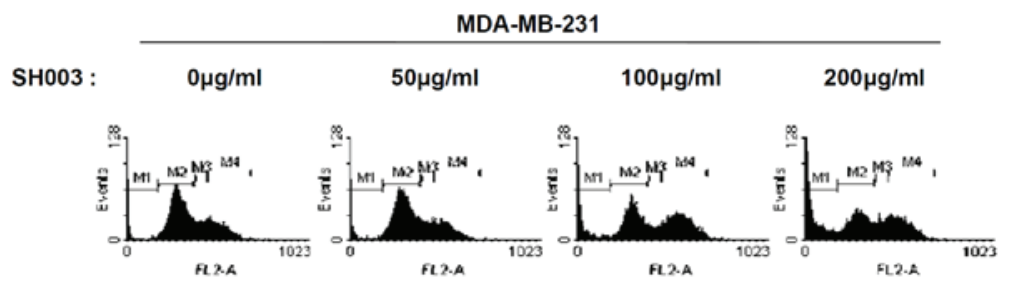

B

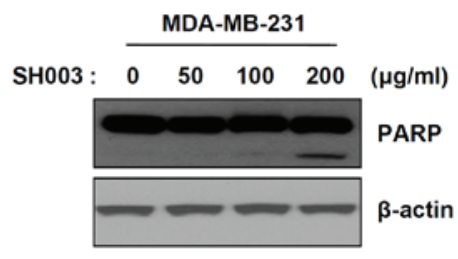

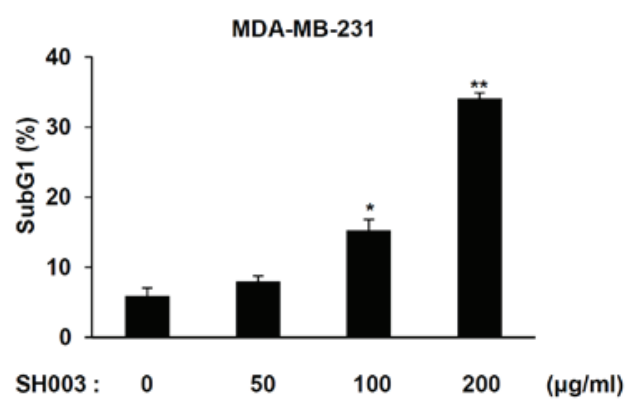

C

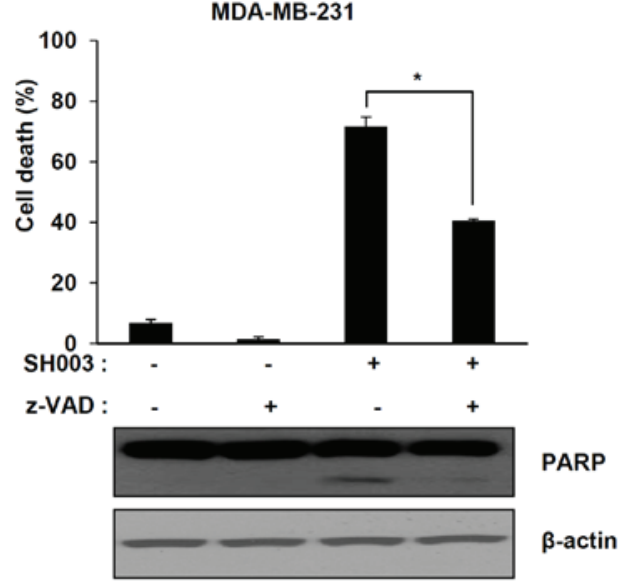

Figure 2. SH003 induces caspase-dependent cell death in TNBC. (A) MDA-MB-231 cells treated with the indicated concentrations of SH003 for 48 h and analyzed by flow cytometry after staining with propidium iodide. Data are presented as the mean \pm standard deviation $(\mathrm{n}=3)$. ${ }^{*} \mathrm{P}<0.05$ and ${ }^{* *} \mathrm{P}<0.01, \mathrm{compared}$ with the untreated cells. (B) MDA-MB231 cells were treated with the indicated concentrations of SH003 for 48 h. Cell lysates were analyzed by western blotting using an anti-PARP antibody. The $\beta$-actin level was used as a loading control. (C) MDA-MB-231 cells were pretreated with 100 mM Z-VAD, a pan-caspase inhibitor, followed by SH003 $(200 \mu \mathrm{g} / \mathrm{ml})$ for $48 \mathrm{~h}$. Cell death was determined by a trypan blue exclusion assay. Data are presented as the mean \pm standard deviation $(n=3)$. ${ }^{*} \mathrm{P}<0.05$, compared with cells treated with SH003 only. TNBC, triple-negative breast cancer; PARP, poly ADP ribose polymerase.

It was demonstrated that SH003 induced p73-mediated apoptosis in p53 mutant MDA-MB-231 cells. p73 expression in MDA-MB-231 cells was observed following treatment with $\mathrm{SH} 003$ using western blot analysis. The p73 protein levels in MDA-MB-231 cells treated with SH003 increased in a dose-dependent manner (Fig. 3A). To confirm that MDA-MB-231 cell death induced by SH003 was correlated with p73, the effect of knockdown of endogenous p73 using small interfering RNAs in MDA-MB-231 cells was examined. Cells were transfected with scrambled siRNA or p73 siRNA, followed by treatment with SH003. Transfected p73 siRNA decreased cell death and PARP cleavage compared with scrambled siRNA treatment (Fig. 3B; $\mathrm{P}<0.05$ compared with SH003 single-treated scramble cells). Additionally, cell death was confirmed using flow cytometric analysis. The number of cells in the sub-G1 phase following SH003 treatment was decreased in the p73 siRNA-transfected cell line compared with the scrambled siRNA-transfected cell line (Fig. 3C; $\mathrm{P}<0.05$ compared with $\mathrm{SH} 003$ single-treated scramble cells). These results indicated that the induction of $\mathrm{p} 73$ expression by SH003 leads to the apoptosis of MDA-MB-231 cells.

SHOO3 sensitizes paclitaxel-induced MDA-MB-231 cell death. Paclitaxel (taxane) is a commonly used treatment in conjunction with other anticancer agents for TNBC; however, paclitaxel treatment occasionally fails due to drug resistance.
It was demonstrated that $\mathrm{SH} 003$ in combination with paclitaxel synergistically increases cell death in TNBC cell compared with individual treatments (Fig. 4A; $\mathrm{P}<0.05$ compared with cells treated with $\mathrm{SH} 003$ or paclitaxel only). Western blot analyses indicated that $\mathrm{SH} 003$ in combination with paclitaxel increased the levels of cleaved caspase-3 in MDA-MB-231 cells but did not alter p73 expression (Fig. 4B). These results indicate that $\mathrm{SH} 003$ in combination with paclitaxel synergistically enhances apoptosis in TNBC cells.

\section{Discussion}

TNBC accounts for 10-20\% of all types of breast cancer (24). TNBC is an aggressive histological subtype with limited treatment conditions and poor prognosis following standard chemotherapy. The anticancer effects of commonly used chemotherapeutic agents, such as paclitaxel, doxorubicin and cisplatin are limited to cure patients with TNBC due to acquired drug resistance and toxicity (9). The present study focused on anticancer therapy for TNBC to overcome resistance against conventional therapies.

The present chemotherapeutic agents for TNBC are DNA-damaging agents (25). In the DNA-damage pathway, tumor suppressor p53 is important in anticancer actions of DNA-damaging agents (26). A recent study reported that regulation of p53-mediated apoptotic signaling occurs in a 
A

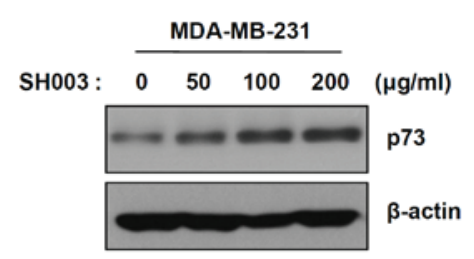

B



C

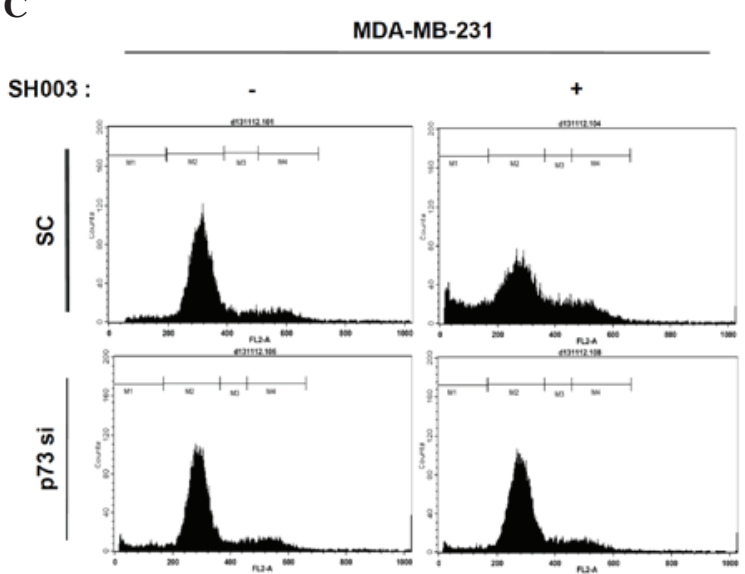

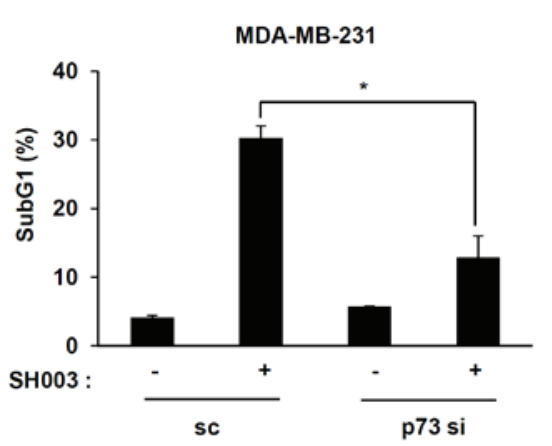

Figure 3. Induction of p73 expression by SH003 leads to apoptosis in TNBC. (A) MDA-MB231 cells were treated with the indicated concentrations of SH003 for $48 \mathrm{~h}$. Cell lysates analyzed by western blotting using an anti-p73 antibody. $\beta$-actin was used as a loading control. (B) MDA-MB231 cells were transfected with scrambled siRNA or p73 siRNA and then incubated with or without SH003 $(200 \mu \mathrm{g} / \mathrm{ml})$ for $48 \mathrm{~h}$. Cell death was determined by a trypan blue exclusion assay. Data are presented as the mean \pm standard deviation $(n=3)$. Cell lysates analyzed by western blotting using anti-p73 and anti-PARP antibodies. $\beta$-actin levels were used as loading controls. (C) MDA-MB231 cells were transfected with scrambled siRNA or p73 siRNA, incubated with or without SH003 $(200 \mu \mathrm{g} / \mathrm{ml})$ for $48 \mathrm{~h}$, and then analyzed by flow cytometry after staining with propidium iodide. Data are presented as the mean \pm standard deviation $(\mathrm{n}=2)$. * $\mathrm{P}<0.05$ compared with SH003-treated scramble cells.
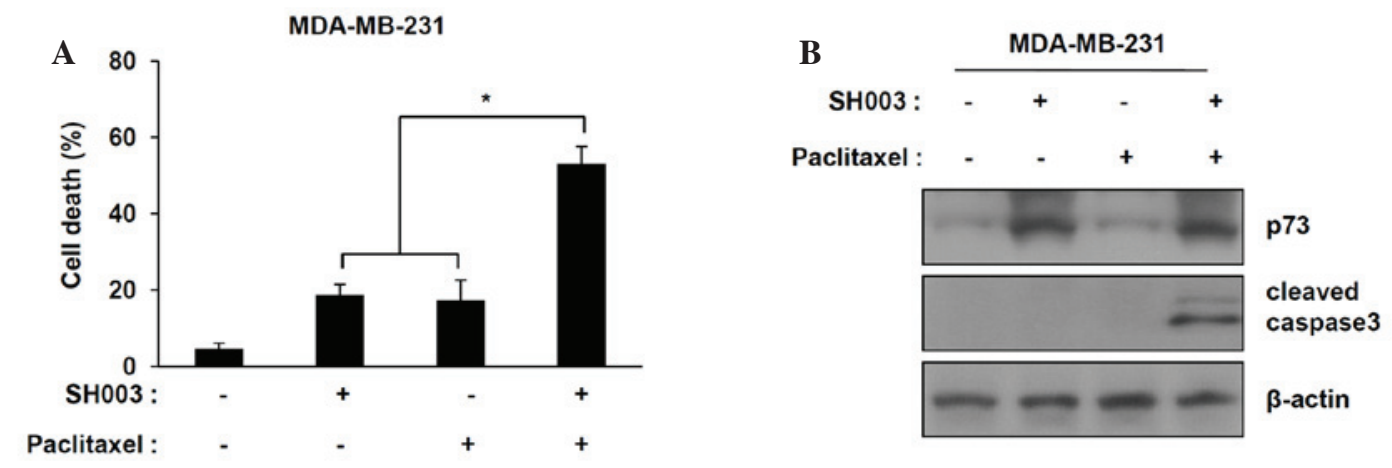

Figure 4. SH003 sensitizes paclitaxel-induced cell death in MDA-MB-231 cells. MDA-MB-231 cells were treated with SH003 (100 $\mu \mathrm{g} / \mathrm{ml})$ alone, paclitaxel $(10 \mu \mathrm{M})$ alone or a combination of the two for $48 \mathrm{~h}$. (A) Cell death was determined by a trypan blue exclusion assay. Data are presented as the mean \pm standard deviation ( $\mathrm{n}=3$ ). ${ }^{*} \mathrm{P}<0.05$ compared with SH003 or paclitaxel single-treated scramble cells. (B) Cell lysates were analyzed by western blotting using anti-p73 and anti-caspase 3 antibodies. $\beta$-actin was used as a loading control.

p73-dependent manner, which results in enhanced apoptosis in p53-deficient TNBC (9). The functional and structural similarities of p53 and p73 have been previously reported (10).
It is also known that p73 can replace the function of p53 in response to DNA damage in p53-deficient cancers. p73 is not frequently mutated in cancers and regulates p53 target genes, 
such as Bax and Noxa in p53-deficient cancers $(27,28)$. The key role of p73 in anti-cancer effects for p53-deficient TNBC was identified.

Identification and development of traditional herbal medicines has increased due to their potential anticancer effects and minimal side effects. This study demonstrated that SH003 inhibited TNBC growth in a dose-dependent manner. Treatment with SH003 resulted in apoptotic cell death as shown by increased PARP cleavage, a caspase-dependent apoptotic marker. In addition, SH003-induced apoptosis was validated after pretreatment with the pan-caspase inhibitor, $\mathrm{Z}-\mathrm{VAD}$, as this partially decreased cell death in MDA-MB-231 cells.

Notably, apoptotic cell death induced by $\mathrm{SH} 003$ was associated with induction of $\mathrm{p} 73$ expression in TNBC. The anticancer effect of SH003 was validated upon siRNA-mediated knockdown of p73. The results showed that knockdown of p73 decreased apoptotic cell death induced by SH003 treatment. In addition, single treatment with paclitaxel did not result in any specific cell death, while SHOO3 in combination with paclitaxel synergistically increased cell death in TNBC. Therefore, SH003 in combination chemotherapies may aid in overcoming resistance to conventional chemotherapies in TNBC.

The apoptotic cell death induced by $\mathrm{SH003}$ is associated with p73 expression, which indicates that the anticancer effects of SH003 are induced by p73-dependent apoptosis. This study showed that SH003 induced the expression of p73- and caspase-dependent apoptosis. Thus, this study revealed that a traditional herbal medicine, SH003, has a significant anticancer effect via p73-mediated apoptosis in TNBC cells and confirmed p73 as a promising therapeutic target for TNBC.

\section{Acknowledgements}

This study was supported by grants from Basic Science Research Program through the the National Research Foundation of Korea (NRF) grant funded by the Korean government (MEST), Seoul, Republic of Korea (NRF-2013R1A2A2A01067394) to Professor Dong-Hoon Jin, and the Korean Medicine R\&D Project of the Ministry of Health and Welfare to Professor Seong-Gyu Ko (B110043).

\section{References}

1. Millis SZ, Gatalica Z, Winkler J, Vranic S, Kimbrough J, Reddy S, O'Shaughnessy JA: Predictive Biomarker Profiling of $>6000$ Breast Cancer Patients Shows Heterogeneity in TNBC, With Treatment Implications. Clin Breast Cancer 15: 73-481, 2015.

2. Isakoff SJ: Triple-negative breast cancer: Role of specific chemotherapy agents. Cancer J 16: 53-61, 2010.

3. Xu L, Yin S, Banerjee S, Sarkar F and Reddy KB: Enhanced anticancer effect of the combination of cisplatin and TRAIL in triple-negative breast tumor cells. Mol Cancer Ther 10: 550-557, 2011.

4. Haffty BG, Yang Q, Reiss M, Kearney T, Higgins SA, Weidhaas J, Harris L, Hait W and Toppmeyer D: Locoregional relapse and distant metastasis in conservatively managed triple negative early-stage breast cancer. J Clin Oncol 24: 5652-5657, 2006.

5. Lehmann BD, Bauer JA, Chen X, Sanders ME, Chakravarthy AB, Shyr Y and Pietenpol JA: Identification of human triple-negative breast cancer subtypes and preclinical models for selection of targeted therapies. J Clin Invest 121: 2750-2767, 2011.

6. Cancer Genome Atlas Network: Comprehensive molecular portraits of human breast tumours. Nature 490: 61-70, 2012.

7. Prat A and Perou CM: Deconstructing the molecular portraits of breast cancer. Mol Oncol 5: 5-23, 2011.
8. Aas T, Børresen AL, Geisler S, Smith-Sørensen B, Johnsen H, Varhaug JE, Akslen LA and Lønning PE: Specific P53 mutations are associated with de novo resistance to doxorubicin in breast cancer patients. Nat Med 2: 811-814, 1996.

9. Tiwary R, Yu W, Sanders BG and Kline K: $\alpha$-TEA cooperates with chemotherapeutic agents to induce apoptosis of p53 mutant, triple-negative human breast cancer cells via activating p73. Breast Cancer Res 13: R1, 2011.

10. Levrero M, De Laurenzi V, Costanzo A, Gong J, Wang JY and Melino G: The p53/p63/p73 family of transcription factors: Overlapping and distinct functions. J Cell Sci 113: 1661-1670, 2000.

11. Kaelin WG Jr: The p53 gene family. Oncogene 18: 7701-7705, 1999.

12. Rödicker F and Pützer BM: $\mathrm{p} 73$ is effective in p53-null pancreatic cancer cells resistant to wild-type TP53 gene replacement. Cancer Res 63: 2737-2741, 2003.

13. Maurya U and Srivastava S: Traditional Indian herbal medicine used as antipyretic, antiulcer, anti-diabetic and anticancer: A Review. IJRPC 1: 4, 2011.

14. Shin JW, Son JY, Kang JK, Han SH, Cho CK and Son CG: Trichosanthes kirilowii tuber extract induces G2/M phase arrest via inhibition of tubulin polymerization in HepG2 cells. J Ethnopharmacol 115: 209-216, 2008.

15. Cho WC and Leung KN: In vitro and in vivo anti-tumor effects of Astragalus membranaceus. Cancer Lett 252: 43-54, 2007.

16. Cui R, He J, Wang B, Zhang F, Chen G, Yin S and Shen H: Suppressive effect of Astragalus membranaceus Bunge on chemical hepatocarcinogenesis in rats. Cancer Chemother Pharmacol 51: 75-80, 2003.

17. Heo BG, Chon SU, Park YJ, Bae JH, Park SM, Park YS, Jang HG and Gorinstein S: Antiproliferative activity of Korean wild vegetables on different human tumor cell lines. Plant Foods Hum Nutr 64: 257-263, 2009.

18. Kim T, Choi HJ, Kim NJ and Kim DH: Anxiolytic-like effects of ginsenosides $\mathrm{Rg} 3$ and $\mathrm{Rh} 2$ from red ginseng in the elevated plus-maze model. Planta Med 75: 836-839, 2009.

19. Li LK, Kuang WJ, Huang YF, Xie HH, Chen G, Zhou QC, Wang BR and Wan LH: Anti-tumor effects of Astragalus on hepatocellular carcinoma in vivo. Indian J Pharmacol 44: 78-81, 2012.

20. Lv J, Zhao Z, Chen Y, Wang Q, Tao Y, Yang L, Fan TP and Liu C: The chinese herbal decoction danggui buxue tang inhibits angiogenesis in a rat model of liver fibrosis. Evid Based Complement Alternat Med 2012: 284963, 2012.

21. Yang M, Chan GC, Deng R, Ng MH, Cheng SW, Lau CP, Ye JY, Wang L and Liu C: An herbal decoction of Radix astragali and Radix angelicae sinensis promotes hematopoiesis and thrombopoiesis. J Ethnopharmacol 124: 87-97, 2009.

22. Zhang WL, Zheng KY, Zhu KY, Zhan JY, Bi CW, Chen JP, Du CY, Zhao KJ, Lau DT, Dong TT and Tsim KW: Chemical and biological assessment of Angelica herbal decoction: Comparison of different preparations during historical applications. Phytomedicine 19: 1042-1048, 2012.

23. Choi YK, Cho SG, Woo SM, Yun YJ, Park S, Shin YC, Ko SG: Herbal extract SH003 suppresses tumor growth and metastasis of MDA-MB-231 breast cancer cells by inhibiting STAT3-IL-6 signaling. Mediators Inflamm. 2014:492173, 2014.

24. Schwentner L, Wolters R, Koretz K, Wischnewsky MB, Kreienberg R, Rottscholl R and Wöckel A: Triple-negative breast cancer: The impact of guideline-adherent adjuvant treatment on survival - a retrospective multi-centre cohort study. Breast Cancer Res Treat 132: 1073-1080, 2012.

25. O'Reilly EA, Gubbins L, Sharma S, Tully R, Guang MH, Weiner-Gorzel K, McCaffrey J, Harrison M, Furlong F, Kell M, McCann A: The fate of chemoresistance in triple negative breast cancer (TNBC). BBA Clin 3: 257-275, 2015.

26. Essmann F and Schulze-Osthoff K: Translational approaches targeting the p53 pathway for anti-cancer therapy. Br J Pharmacol 165: 328-344, 2012.

27. Melino G, Bernassola F, Ranalli M, Yee K, Zong WX, Corazzari M, Knight RA, Green DR, Thompson C and Vousden KH: p73 induces apoptosis via PUMA transactivation and Bax mitochondrial translocation. J Biol Chem 279: 8076-8083, 2004.

28. Flinterman M, Guelen L, Ezzati-Nik S, Killick R, Melino G, Tominaga K, Mymryk JS, Gäken J and Tavassoli M: E1A activates transcription of p73 and Noxa to induce apoptosis. J Biol Chem 280: 5945-5959, 2005. 